\title{
CORRELAÇÃO DA FLUVIOMETRIA E DE ALGUNS FATORES CLIMÁTICOS SOBRE A PRODUÇÃO PESQUEIRA DE ANCHOVIELLA LEPIDENTOSTOLE (FOWLER, 1911) (TELEOSTEI, ENGRAULIDAE), NO RIO RIBEIRA DE IGUAPE, SÃO PAULO, BRASIL
}

\section{Maria Teresa Duarte Giamas ${ }^{1}$ Luiz Edésio Santos ${ }^{2}$ Harry Vermulm Jr. ${ }^{3}$ José Nilton de Souza ${ }^{3}$}

\begin{abstract}
This research was undertaken in Registro, SP, from January 1979 to December 1982, to verify the relationship between the capture (in kilograms) of Anchoviella lepidentostole (Fowler, 1911) and fluviometric and climatic parameters.

The following results were obtained, utilizing the Pearson index of linear correlation: a) for capture and fluviometric values, $r=-0.84$; $b$ ) for capture and solar radiation, $r=0.63$; c) for capture and pluviometric index, $r=-0.83$; d) for capture and mean air temperature, $r=0.30$.
\end{abstract}

\section{INTRODUÇÃO}

$\mathrm{O}$ município de Registro, situado às margens do Rio Ribeira de Iguape, atua como um dos principais polos de comercialização de pescado, sendo toda a captura para fins comerciais enviado a ele, com exceção da realizada na região de Iguape, localizada a aproximadamente $100 \mathrm{~km}$ de Registro.

Entre as várias espécies de peixes que constituem a fauna desse rio, a que apresenta maior importância econômica é a manjuba ( $A$. lepidentostole Fowler, 1911), peixe anádromo que penetra no rio para desovar (Santos, 1952; Nomura, 1964).

1. Pesquisador Científico - Seção de Aquicultura - Divisão de Pesca Interior - Instituto de Pesca.

2. Pesquisador Científico - Seção de Limnologia - Divisão de Pesca Interior - Instituto de Pesca.

3. Biologistas - Seção de Aquicultura - Divisão de Pesca Interior - Instituto de Pesca. Bolsistas do Conselho Nacional de Desenvolvimento Científico e Tecnológico C N P q . 
Segundo Melo (1978), o gênero Anchoviella ocorre na costa sudeste do Brasil, sendo capturado em larga escala, principalmente na região entre Iguape e Cananéia.

Até 1978, a pesca deste peixe era realizada em uma grande área, abrangendo desde Pedrinha (divisa entre Iguape e Cananéia, na Ilha Comprida) até Registro (bairros de Guaviruva e Jurumirim). A pesca era feita a pouca distância das próprias residências, em virtude da grande quantidade de manjuba em todo o trecho da laguna e do rio. Com o fechamento do Valo Grande, a situação alterou-se radicalmente, pois a manjuba passou a penetrar no rio através de sua foz e a concentração do peixe provocou o ajuntamento dos pescadores naquela área (Ialongo, 1983).

Estes fatos permitem inferir que a captura de manjuba tem decrescido a montante do rio, provocando prejuízos incalculáveis não só para a economia regional mas principalmente para os pescadores que vivem de sua pesca.

Este decréscimo talvez não esteja ligado somente ao fator Valo Grande com a pesca predatória, mas também às condições limnológica do rio e a possíveis modificações de alguns fatores climáticos ambientais.

O índice pluviométrico, para Viner (1975), é muito importante no estudo dos ambientes aquáticos, pois acarreta um aporte de nutrientes e material drenado das áreas marginais, mostrando o acoplamento íntimo entre os ecossistemas terra-água.

Já a temperatura do ar, segundo Henry \& Cury (1981), não tem recebido a devida importância nos trópicos quando relacionados com os ambientes aquáticos.

Neste trabalho são apresentados alguns dos fatores climáticos e fluviométricos que podem ter correlação com a produçãn pesqueira da manjuba no Rio Ribeira de Iguape em Registro.

\section{MATERIAL E MÉTODOS}

No período compreendido entre janeiro/79 a dezembro/82 foram realizados levantamentos diários no mercado municipal de Registro, com $\mathrm{o}$ intuito de obter-se a quantidade $(\mathrm{kg})$ capturada de manjuba ( $\mathrm{A}$. lepidentostole; classificada segundo Figueiredo \& Menezes, 1978) e o tipo de aparelho de pesca utilizado. Paralelamente foram feitas entrevistas junto aos pescadores profissionais, com a finalidade de conhecer o método de captura. Neste método, utiliza-se apenas 1 barco com dois tripulantes, sendo a ponta oposta da rede carregada por 1 pescador que caminha pela margem do rio. Esta rede é constituída por uma panagem de 50 braças de comprimento por 1,5 de altura, cujo formato lembra muto a de um picaré; nas extremidades das mangas são colocados dois calões de madeira, 
com a finalidade de manter as pontas do aparelho convenientemente abertas e para suportarem os esforços feitos sobre os cabos de tração (Carvalho \& Ramos, 1941). Este tipo de rede é utilizado até os dias atuais, sendo vulgarmente conhecida como rede manjubeira.

Os fatores climáticos de temperatura média do ar, precipitação pluviométrica e insolação média foram obtidos junto ao Centro Tecnológico de Hidráulica do Departamento de Águas e Energia Elétrica da Secretaria de Obras e do Meio Ambiente. Com os dados de insolação foram determinados os valores de radiação, através da fórmula de Angstron (Sá, 1973), a partir de medidas do brilho solar e tabelas meteorológicas do Smithsonian Meteorological Table (Villa Nova, 1967).

A fórmula de Angstron é $\mathrm{Q}_{\mathrm{s}}=\mathrm{Q}_{\mathrm{o}}(\mathrm{a}+\mathrm{b} \cdot \mathrm{n} / \mathrm{N})$, onde $\mathrm{Q}_{\mathrm{s}}=$ energia que atinge uma superfície horizontal na superfície da terra em $\mathrm{cal} / \mathrm{cm}^{2} / \mathrm{dia} ; \mathrm{Q}_{0}=$ energia que atingiria uma superfície horizontal na superfície da terra, na ausência de atmosfera, medida em $\mathrm{cal} / \mathrm{cm}^{2} / \mathrm{dia} ; a$ e $b$ = parâmetros (calculados através de uma correlação entre os dados experimentais obtidos a partir de actinógrafos e heliográfos). As medidas obtidas por Villa Nova, Reichardt \& Ortolani (1968) para o Estado de São Paulo foram: $a=0,24 \mathrm{e} \mathrm{b}=0,58 ; \mathrm{n}=$ insolação ( $\mathrm{n}$. de horas desde o levantamento até o por do sol).

Os valores fluviométricos mensais do Rio Ribeira de Iguape foram obtidos junto ao Posto Fluviométrico de Registro, prefixo 4F - 2R, pertencente ao Departamento de Águas e Energia Elétrica da Secretaria de Obras e do Meio Ambiente.

Os valores de captura total (quilos), índice pluviométrico (mm), temperatura média do ar $\left({ }^{\circ} \mathrm{C}\right)$, radiação solar $\left(\mathrm{cal} / \mathrm{cm}^{2}\right)$ e fluviométrico $(\mathrm{mm})$ foram agrupados mensal e anualmente.

\section{Métodos Estatísticos}

Para a análise estatística foram utilizados: Teste de variância de dois critérios (Sokal \& Rohlf, 1969), e, quando houve diferença significativa, o Teste de Tukey (Pimentel Gomes, 1966); entre captura e os demais fatores (climáticos e fluviométricos), calculou-se o Coeficiente de correlação linear de Pearson (Santos, 1978).

\section{RESULTADOS E DISCUSSÃO}

Os resultados expressos na Tabela 1 indicam a variabilidade da captura (em quilos) de Anchoviella entre os meses, com F calculado igual a 4,20 (significativo ao nível de $1 \%$ ) e o Teste de Tukey demonstrando que esta diferença é significante $\mathrm{P}<0,05$. Entre os anos, com $\mathrm{F}$ calculado igual a 5,26 (significativo ao nível de 1\%), o Teste de Tukey mostrou que 
a diferença foi significante ao nível de $5 \%$ sendo que em 1979 foi maior que nos demais anos.

A correlação entre meses e anos frente à captura, fatores climáticos e fluviometria (Tabela 1) demonstraram:

Radiação solar: Para os ecossistemas aquáticos, a radiação solar, sem dúvida, é o fator abiótico mais importante, pois apresenta quatro efeitos quando atinge superfícies líquidas (Blair \& Fite, 1964); maior penetração na água do que na terra; responsável pela distribuição de calor na massa de água; utilização parcial na evaporação da água e o aumento de calor específico da água.

A diferença entre os meses com $\mathrm{F}$ calculado igual a 417,07 foi significante ao nível de $1 \%$. O teste de Tukey mostrou que janeiro, fevereiro e março são significativamente maiores ao nível de $1 \%$ que os meses de junho, julho, agosto, abril e maio. Entre os anos, of calculado foi 2,92 (significativo ao nível de $1 \%$ ); pelo Teste de Tukey demonstrou-se que 1979 foi maior que 1982. Na Figura 1, o índice de correlação de Pearson monstrou que entre captura e radiaçâo solar foi $r=0,63$.

Temperatura média do ar: Do ponto de vista climatológico, a temperatura, com suas constantes variações, determina as influências sobre os seres vivos.

O teste de variância mostrou diferença significativa ao nível de $1 \%$ para os meses com $F=27,30$ e para os anos $F=8,21$. O teste de Tukey confirmou que os meses de janeiro, fevereiro e março foram significativamente diferentes que os demais meses com $\mathrm{P}<0,01$. Entre os anos verificou-se que $1979 / 80$ são diferentes de 1981 , ao nível de $5 \%$ e $1 \%$ respectivamente. A Figura 2 mostra que o índice de correlação de Pearson entre captura e temperatura média do ar foi $\mathrm{r}=0,30$, portanto muito baixo.

Segundo Henry \& Cury (1981), isto ocorre porque os efeitos da temperatura do ar sobre os ambientes aquáticos são indiretos.

Índice Pluviométrico: $\mathrm{O}$ teste de variância para o índice pluviométrico mostrou diferença significativa ao nível de $1 \%$ com $F=14,66$ para os meses e $\mathrm{F}=5,97$ para os anos. O Teste de Tukey confirmou o predomínio dos meses de janeiro a maio sobre os demais meses e entre os anos houve significância ao nível de $1 \%$ do ano de 1982 sobre 1979. Na Figura 3 observou-se que o índice de correlação de Pearson entre captura e índice pluviométrico foi $r=0,83$.

Fluviometria: $O$ estudo das enchentes fluviais do Rio Ribeira de Iguape foi analisado, observando-se que o teste de variância foi não significativo (n.s.) com $F=1,74$ para os meses e $F=1,08$ para os anos. Pelo índice de correlação de Pearson (Figura 4) observou-se $r=-0,84$.

A correlação negativa observada na pluviometria e fluviometria de- 
monstram claramente que quando estes dois fatores anumentam, ocorre uma menor captura de manjubas.

\section{CONCLUSÕES}

1. Houve correlação positiva com $r=0,63$ entre captura (em quilos) e a radiação solar, demonstrando que em 1979 ocorreu maior captura e radiação solar, ocorrendo o oposto em 1982 para estes 2 fatores.

2. A correlação foi positiva com $r=0,30$ entre captura (em quilos) e temperatura média do ar, porém não significativa.

3. Através da relação entre captura e pluviometria observou-se uma correlação negativa $(r=-0,83)$, o mesmo ocorrendo entre captura e fluviometria com $r=-0,84$, demonstrando que no ano de 1979 houve maior captura e menores índices pluviométricos e fluviométricos.

\section{REFERÊNCIAS}

Blair, T. A. \& R. C. Fite, 1964. Meteorologia, 406 pp. Ao Livro Técnico, Rio de Janeiro. Carvalho, J. P. \& F. A. de Ramos, 1941. O desenvolvimento da pesca e a industrialização da manjuba no Rio Ribeira. Bol. Ind. An. 4(1): 38-59.

Figueiredo, J. L. \& N. A. Menezes, 1978. Manual de peixes marinhos do sudeste do Brasil. $I I$ - Teleostei (1). São Paulo, Museu de Zoologia, USP, São Paulo, 110 pp.

Henry, R. \& P. R. Curi, 1981. Influências de parâmetros climatológicos sobre alguns fatores físico-químicos da água na Represa do Rio Pardo (Botucatu, SP). Revta. bras. Biol., Rio de Janeiro 41(2): 299-306.

Ialongo, C., 1983. “O Estado de São Paulo”, 104(33.377): 22.

Melo, M. J. de, 1978. Estimativa preliminar da biomassa e o potencial pesqueiro de engraulídeos na região sul do Brasil. Programa de Pesquisa e Desenvolvimento Pesqueiro do Brasil, Brasília, SUDEPE (Documentos Técnicos, 29), 40 pp.

Nomura, H., 1964. Considerations on the sampling of marine fish. IV: Sampling of "Anchoviella hubbsi”' Hildebrand. Revta. bras. Biol. 24(4): 365-370.

Pimentel Gomes, F., 1966. Curso de Estatística Experimental, 404 pp. Escola Superior de Agricultura "'Luiz de Queiroz", Piracicaba.

Sá, D. F., 1973. Alguns aspectos da energia solar em Mandacarú. Bol. Rec. Nat., Recife $11(1 / 2): 11-26$.

Santos, E., 1952. Nossos peixes marinhos (Vida e costumes dos peixes do Brasil), 276 pp. F. Briguiet \& Cia, Rio de Janeiro.

Santos, E. P. dos, 1978. Dinâmica de populações aplicada à pesca e pisciculturà, 129 pp. Hucitec/EDUSP, São Paulo.

Sokal, R. R. \& J. Rohlf, 1969. Biometry, State University of New York at Stonebrooke W. H. Freeman and Companhy, New York.

Villa Nova, N.A., 1967. A estimativa da evaporação potencial no Estado de São Paulo. (Dissertação de Doutorado, Escola Superior de Agricultura “Luiz de Queiroz"', Universidade de São Paulo).

Villa Nova, N. A., K. Reichardt \& A. A. Ortolani, 1968. Principais métodos climáticos de estimativa e de medida de perda de água de superfícies naturais, $31 \mathrm{pp}$. Apostila do Curso de Física e Meteorologia da Escola Superior de Agricultura "Luiz de Queiroz", Piracicaba.

Viner, A. B., 1975. The suplly of minerals to tropical rivers and lakes (Uganda). In:

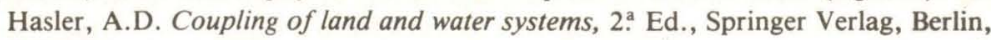
227-261. 


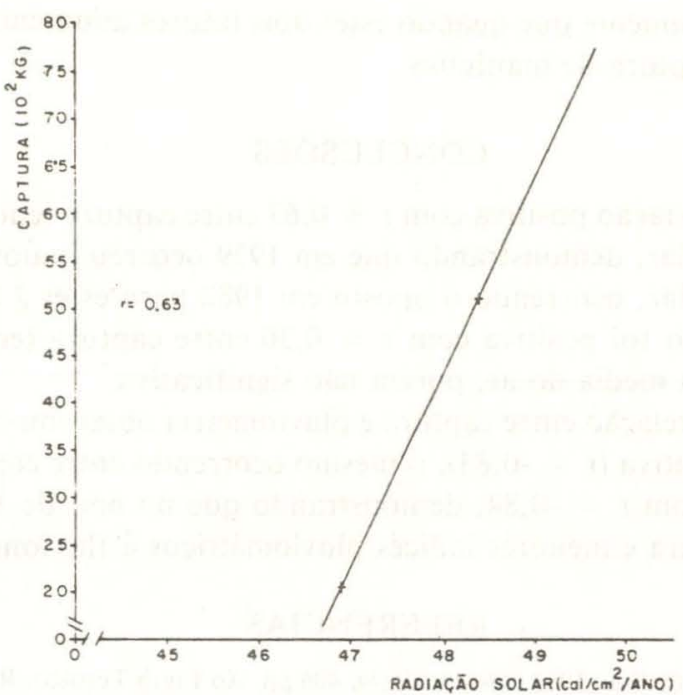

Fig. 1: Correlação linear de Pearson entre captura (kg) de Anchoviella lepidentostole (Fowler, 1911) e radiação solar ( $\left.\mathrm{cal} / \mathrm{cm}^{2} / \mathrm{ano}\right)$ do Rio Ribeira de Iguape, no período de 1979 a 1982.

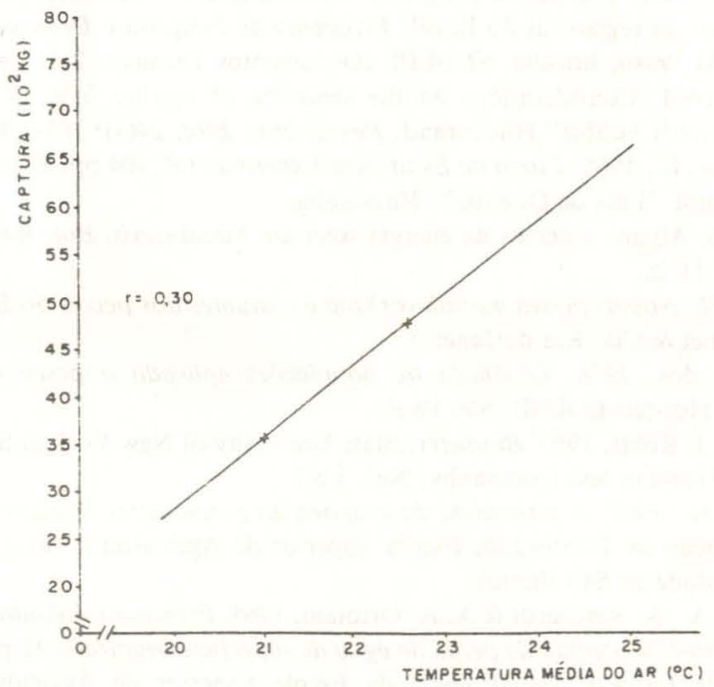

Fig. 2: Correlação linear de Pearson entre captura (kg) de Anchoviella lepidentostole (Fowler, 1911) e temperatura média do ar $\left({ }^{\circ} \mathrm{C}\right)$ do Rio Ribeira de Iguape, no período de 1979 a 1982. 


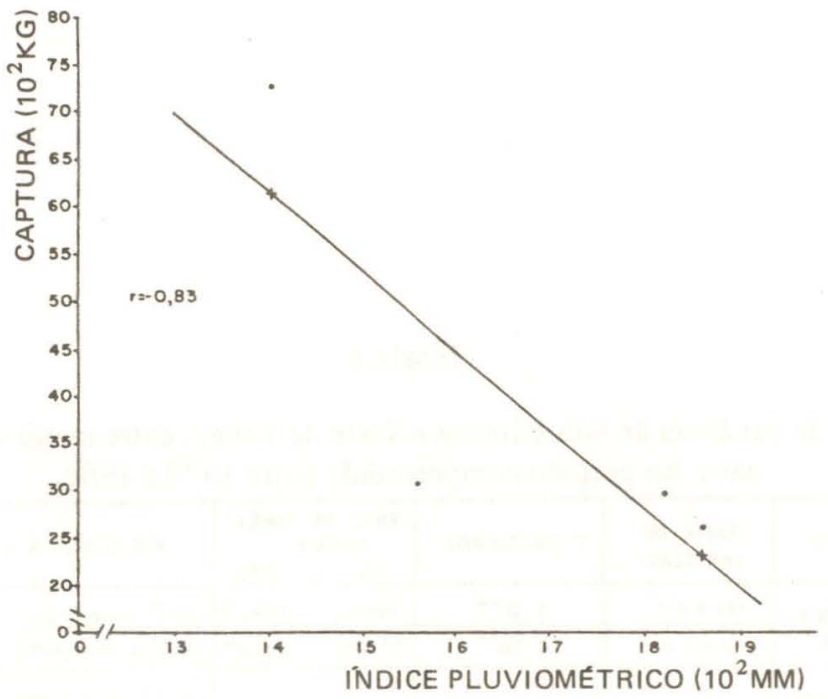

Fig. 3: Correlação linear de Pearson entre captura (kg) de Anchoviella lepidentostole (Fowler, 1911) e índice pluviométrico $\left(10^{2} \mathrm{~mm}\right)$ do Rio Ribeira de Iguape, no período de 1979 a 1982.

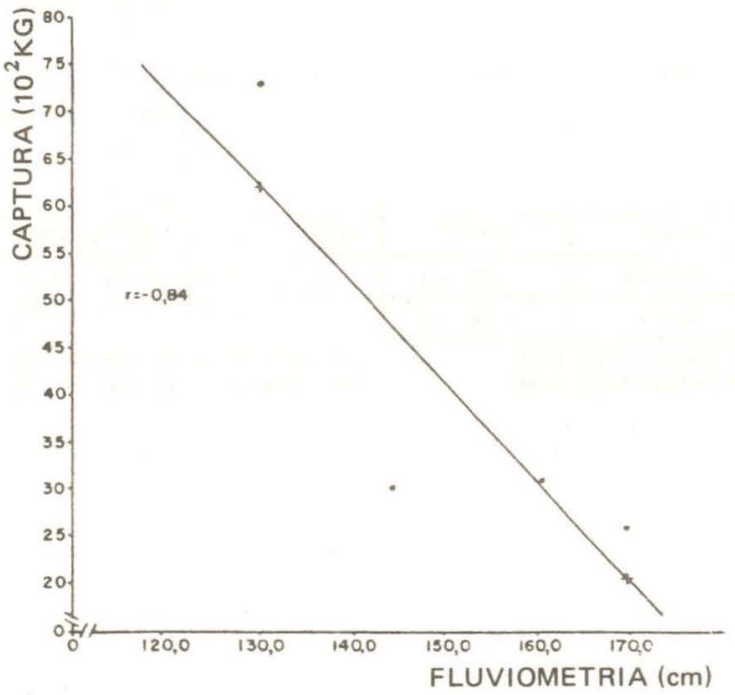

Fig. 4: Correlação linear de Pearson entre captura $(\mathrm{kg})$ deAnchoviella lepidentostole (Fowler, 1911 ) e fluviometria (cm) do Rio ribeira de Iguape, no período de 1979 a 1982. 
Tabela 1

Teste de variância de dois critérios e Teste de Tukey, entre meses e entre anos, no período compreendido entre 1979 a 1982.

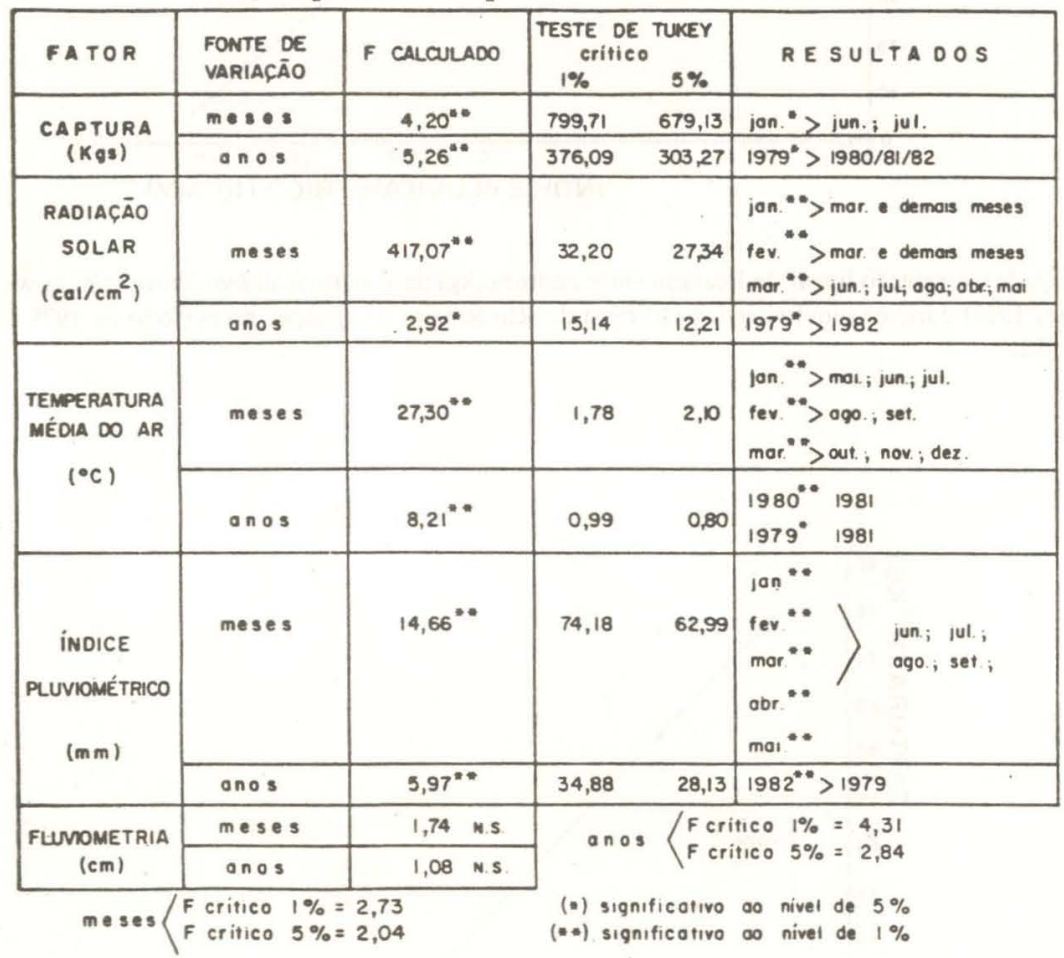

